\title{
OC-101 IMPACT OF ON-SITE ADEQUACY ASSESSMENT FOR EUS FNA OF SOLID PANCREATIC LESIONS
}

doi:10.1136/gut.2011.239301.101

S Chatterjee, ${ }^{*}$ V Wadehra, ${ }^{2} \mathrm{~J}$ Cunningham, ${ }^{2} \mathrm{~J}$ Leeds, $^{1} \mathrm{~K}$ Oppong, ${ }^{1} \mathrm{M}$ Nayar ${ }^{1}{ }^{1}$ Department of Gastroenterology, Freeman Hospital, Newcastle upon Tyne, UK; ${ }^{2}$ Department of Cytopathology, Freeman Hospital, Newcastle upon Tyne, UK

Introduction There are a number of factors which can influence the accuracy of EUS FNA but the presence of an in-room cytotechnician (IRC) has been shown to be one of the important factors. The aim of this study was to establish if the introduction of an IRC improved the diagnostic accuracy of EUS guided FNA of solid pancreatico biliary lesions

Methods This is a prospective study and includes all patients with solid pancreatico biliary lesions who underwent EUS FNA from April 2009 to September 2010. We have been performing EUS FNA since 2003 but did not have an IRC till this period. The IRC attended 2 of the 4 EUS lists and therefore there were two groups identified: Group 1 - Cytotechnician absent; Group 2 - Cytotechnician present. Final diagnosis was based on a positive diagnosis on cytology, other forms of tissue acquisition and/or a year's follow up for the benign/ indeterminate cases. Only patients with a final diagnosis were included in the study.

Results The final results are shown in table 1.

We compared our data to the 6 months prior to this study (October 2008-March 2009) when there was no IRC available. The accuracy, sensitivity, specificity, PPV and NPV during this period were $86 \%, 82 \%, 100 \%, 100 \%$ and $57.6 \%$ respectively. The inadequate aspirate rate during this period was $14.2 \%$. There was no statistical difference when this data was compared to either Groups 1 or 2.

Conclusion This study shows that the presence of an IRC does not necessarily improve the diagnostic accuracy of EUS FNA of pancreatobiliary lesions. There are a number of factors which influence the results but experience of the cytopathologist/cytotechnician has shown to be one of the important factors. By keeping the number of inadequate aspirates low and reducing the number of highly suspicious samples the accuracy

Table 1 OC-101 Comparative results for both groups of patients.

\begin{tabular}{lccc}
\hline & $\begin{array}{c}\text { Group 1 } \\
\mathbf{8 2} \text { patients }\end{array}$ & $\begin{array}{c}\text { Group 2 } \\
\mathbf{9 7} \text { patients }\end{array}$ & p Value \\
\hline Mean age (range) & $64.4(22-89)$ & $63.1(33-83)$ & NS \\
Mean passes(range) & $4.01(1-8)$ & $4.3(1-8)$ & NS \\
Inadequate aspirate rate & $7.3 \%$ & $5.1 \%$ & NS \\
Accuracy (\%) & 89 & 91 & NS \\
Sensitivity (\%) & 88 & 90 & NS \\
Specificity (\%) & 100 & 100 & NS \\
Positive predictive value (\%) & 100 & 100 & NS \\
Negative predictive value (\%) & 50 & 69 & NS \\
\hline
\end{tabular}


of the test can be improved. Large studies may be required to show a significant difference. Cost effectiveness and experience of the cytopathologist/cytotechnician should be taken into consideration when setting up this service.

Competing interests None.

Keywords in room cytopathology for EUS FNA, pancreatic cancer. 